\title{
Progress in the treatment of infantile hemangioma
}

\author{
Zhao-Yang Chen", Qing-Nan Wang", Yang-Hui Zhu, Ling-Yan Zhou, Ting Xu, Zhi-Yao He, Yang Yang \\ Department of Pharmacy, State Key Laboratory of Biotherapy and Cancer Center, West China Hospital, Sichuan University and Collaborative \\ Innovation Center of Biotherapy, Chengdu 610041, China \\ Contributions: (I) Conception and design: ZY He; (II) Administrative support: T Xu, Y Yang; (III) Provision of study materials or patients: ZY Chen, \\ QN Wang; (IV) Collection and assembly of data: ZY Chen, QN Wang, YH Zhu, LY Zhou, ZY He, Y Yang; (V) Data analysis and interpretation: ZY \\ Chen, QN Wang, YH Zhu, LY Zhou, ZY He, Y Yang; (VI) Manuscript writing: All authors; (VII) Final approval of manuscript: All authors. \\ \#These authors contributed equally to this work. \\ Correspondence to: Zhi-Yao He, PhD; Yang Yang, PhD. Department of Pharmacy, West China Hospital, Sichuan University, No. 37 Guo Xue Xiang, \\ Chengdu, Sichuan 610041, China. Email: heyaode@163.com; zhiyaohe@scu.edu.cn; yang2012@scu.edu.cn.
}

\begin{abstract}
Infantile hemangioma $(\mathrm{IH})$ is a common benign tumor, which mostly resolves spontaneously; however, children with high-risk IH need treatment. Currently, the recognized first-line treatment regimen for IH is oral propranolol, but research on the pathogenesis of IH has led to the identification of new therapeutic targets, which have shown good curative effects, providing more options for disease treatment. This article summarizes the applications of different medications, dosages, and routes of administration for the treatment of IH. In addition to drug therapy, this article also reviews current therapeutic options for IH such as laser therapy, surgical treatment, and observation. To provide the best treatment, therapeutic regimens for IH should be selected based on the child's age, the size and location of the lesion, the presence of complications, the implementation conditions, and the potential outcomes of the treatment.
\end{abstract}

Keywords: Infantile hemangioma (IH); beta blocker; medication; laser; surgery

Submitted Sep 27, 2019. Accepted for publication Oct 05, 2019.

doi: $10.21037 /$ atm.2019.10.47

View this article at: http://dx.doi.org/10.21037/atm.2019.10.47

\section{Introduction}

Vascular diseases in infants and children are divided into two broad categories: vascular tumors and vascular malformations. Infantile hemangiomas (IHs) are the most common type of vascular tumors, with an incidence ranging from $4 \%$ to $5 \%(1-3)$. Up to $10 \%$ of non-Hispanic Caucasian infants have this disease; it also affects more females than males (4) and is more prevalent in premature, low birth weight, and multiple-birth babies $(5,6)$. IH is a benign vascular tumor formed by abnormal proliferation of endothelial cells and vascular proliferation and is distributed in the head, neck, and face (4).

In most cases, the growth of hemangiomas in infants is the fastest and most significant in infants $1-3$ months of age, and gradually decreases after 5 months of age (7). IHs are usually harmless and can gradually resolve spontaneously after 1 year of age without any intervention. However, approximately $5-10 \%$ of IHs is destructive (8) and may lead to telangiectasia, cicatrization, ulcers, hyperpigmentation, and hemangioma in the eye, all of which can affect vision and cause other serious problems such as disfigurement or even death. Thus, intervention is needed to prevent the adverse consequences of these high-risk IHs. The clinical guidelines for IH management recommend early intervention (within 1 month of age). With the continuous exploration and optimization of therapeutic regimens in recent years, many curative therapeutic regimens have emerged and been applied in clinical practice including oral medications, injectable medications, topical medications, laser therapy, surgical treatment, and observation. Many of these studies have focused on drug therapy, and several types of therapeutic drugs have become available. We here review the current progress in therapeutic regimens and provide a basis for treatment decisions in clinical practice. 


\section{IH pathogenesis}

The specific etiology and pathogenesis of IHs have not been fully understood, but some recent studies have supplied some in-depth understanding of the pathogenesis of IHs. Angiogenesis and vasculogenesis are considered the main pathogenic mechanisms during new vessel formation in IH. Studies have shown that basic fibroblast growth factor (bFGF), vascular endothelial growth factor (VEGF), vascular endothelial growth factor receptor (VEGFR), glucose transporter isoform 1 (GLUT1), matrix metalloproteinase-9 (MMP-9), proliferating cell nuclear antigen, type IV collagenase, and angiotensin are highly expressed in IHs in the proliferative phase inducing blood vessel proliferation (9-13). The number of mast cells and the level of tissue inhibitors of metalloproteinases (TIMPs) increases while the content of bFGF decreases in regressive hemangioma, causing neovascularization due to the imbalance of positive and negative angiogenic regulator expression in this hemangioma and adjacent normal tissues. Hypoxia is an inducing factor of revascularization and angiogenesis. In hypoxic conditions, pro-angiogenesis is stronger than anti-angiogenesis, so the balance moves towards pro-angiogenesis. This angiogenic switch stimulates tumor cells and stroma cells to express angiogenic factors $(14,15)$ including VEGF, bFGF, GLUT1, stromal cellderived factor-1 $\alpha$ (SDF-1 $\alpha)$, hypoxia-inducible factor-1 $\alpha$ (HIF-1 $\alpha$ ), platelet-derived growth factors (PDGFs), lysophosphatidic acid (LPA), and angiotensin (11) to promote angiogenesis. Studies have shown that folliclestimulating hormone (FSH) is expressed in IH tissues, and the FSH receptor is enriched in IH-adjacent cells, suggesting that this cell type may be involved in tumor pathogenesis $(16,17)$. Studies have also shown that FSH promotes the expression of VEGF and HIF- $1 \alpha(18,19)$.

\section{Classification and clinical features of IHs}

A complete IH classification developed by the International Society for Study of Vascular Anomalies (ISSVA) in 1996 has been well-adopted internationally and has been continuously revised. It was first revised in 2014, and the complete revised version was published in 2015. In 2018, the ISSVA revised the IH classification system again (20), making it the most recent classification scheme. IHs could be classified according to the depth of the lesions in the soft tissues as follows: (I) superficial hemangioma has the clinical manifestation of reddish or bright red papules, nodules, or plaque on normal skin, and a few of them may be diffuse hyperplastic. Superficial IH with a strawberrylike appearance, also known as strawberry hemangioma or capillary hemangioma, is called superficial hemangioma (21) and is the most common type of IH; (II) deep hemangioma, also called sponge-like hemangioma, is a raised nodule found below the skin surface and is deformed by pressure. It often appears bluish, with or without telangiectasia patches in the center, and is uncommon; (III) mixed (superficial + deep) hemangioma is a combination of both superficial and deep hemangiomas. This type can grow rapidly with extensive area involvement and is common; (IV) reticular/ abortive/minimal growth hemangiomas; and (V) others form the last categories of IHs. IHs can also be classified as follows based on their anatomical location: (I) focal IH has a clear localized lesion possibly originated from a center; (II) multifocal IH has multiple and scattered lesions originating from multiple centers of the lesions; (III) segmental IH often has a plaque or patchy anatomical region and is distributed in a linear or map-like manner in specific skin areas usually $>5 \mathrm{~cm}$ diameter; and (IV) indeterminate IH is a lesion with unclear positioning and does not belong to a segment (commonly known as partial segmental IH).

\section{Therapeutic regimens}

\section{Drug therapy}

The currently available drugs for therapeutic regimens include oral medications, topical medications, and injectable medications applied topically and systemically. Among them, oral medications and topical $\beta$-blockers have been most frequently studied and have shown excellent curative effects.

\section{Oral medications}

Beta-adrenergic blocking agents ( $\beta$ blockers)

In 2009, Leaute-Labreze et al. (22) were the first to report the application of propranolol for the treatment of 11 cases of severe IHs with good therapeutic outcomes. Since then, studies on $\beta$ blockers in IH treatment have been initiated, and studies of the application of propranolol in IH treatment have been reported in recent years. Over 500 case reports and case series involving more than 2,000 patients have been published (8). These include prospective studies $(23,24)$, randomized controlled trials $(25,26)$, retrospective studies (27-31), case reports (32-34), and systematic reviews $(35,36)$. Propranolol has become the first-line treatment 
for $\mathrm{IH}$ and has been reported in different major guidelines $(7,37)$, expert consensus $(8,38,39)$, and in the Childhood Vascular Tumors Treatment $\left(P D Q^{\circledR}\right)$-Health Professional Version (40), as the preferred and recommended medication.

In March 2014, the US Food and Drug Administration approved Hemangeo (41), a propranolol hydrochloride oral solution, for the treatment of proliferating IHs. The recommended therapeutic window is from 5 weeks to 5 months, with a starting dose of $0.6 \mathrm{mg} / \mathrm{kg}$ twice daily (at least 9 hours apart). The dosage is increased to $1.1 \mathrm{mg} / \mathrm{kg}$ twice daily, 1 week later and further increased to $1.7 \mathrm{mg} / \mathrm{kg}$ twice daily for six consecutive weeks after 2 weeks of initial treatment. The recommended dose for Chinese children is $1.0-2.0 \mathrm{mg} / \mathrm{kg} / \mathrm{d}$, divided into two oral administrations (at least 8 hours apart), and the recommended dosage for children in Western countries is $2.0-3.0 \mathrm{mg} / \mathrm{kg} / \mathrm{d}$. It is recommended that children under 1 month of age or weighing less than $5 \mathrm{~kg}$ start with an initial dose of $1.0 \mathrm{mg} / \mathrm{kg} / \mathrm{d}$, divided into two oral administrations; if they have no serious adverse reaction (AR) and can tolerate the initial dose, the dosage can be gradually increased by $0.5 \mathrm{mg}$ steps up to $2.0 \mathrm{mg} / \mathrm{kg} / \mathrm{d}$, divided into two oral administrations. The recommended dose for children older than 1 month of age or weighing more than $5 \mathrm{~kg}$ is $2.0 \mathrm{mg} / \mathrm{kg} / \mathrm{d}$, divided into two oral administrations. For premature infants, low birth weight infants, and children with poor general conditions, the initial dose is $0.5 \mathrm{mg} / \mathrm{kg} / \mathrm{d}$, divided into two oral administrations; if they have no obvious AR and can tolerate the initial dose, the dosage can be gradually increased to $2.0 \mathrm{mg} / \mathrm{kg} / \mathrm{d}$ (divided into three oral administrations) when they reach at least 6 months of age.

The therapeutic mechanism of propranolol in IHs $(42,43)$ may be: the reduction of endothelial cell proliferation in hemangiomas by increasing the expression of pro-apoptotic genes $p 53$ and $B a x$, and reducing expression of the antiapoptotic gene $B c l-x l$ to induce the apoptosis of endothelial cells; downregulation of FGF-2, HIF-1 $\alpha$, VEGF-165, and VEGF-2 expression; vasoconstriction; intervention of nitric oxide $(\mathrm{NO})$ production to impair the angiogenesis of hemangioma stem cells; promotion of lipolysis of hemangioma stem cells $(44,45)$; or promotion of anti-angiogenesis mediated by thrombospondin-1 and blockage of angiogenesis mediated by nuclear factor-kappa B (NF- $\mathrm{kB})$ (46).

Propranolol is contraindicated in the following situations: cardiogenic shock, sinus bradycardia, hypotension, secondto third-degree atrioventricular block, heart failure, history of airway responsiveness (e.g., asthma and poor ventilation), aortic stenosis, and allergic reaction to propranolol.
The common side effects $(35,47)$ of propranolol include gastrointestinal discomfort, sleep disorders, agitation, and body temperature fluctuations. The serious ARs reported with propranolol treatment include atrioventricular block, bradycardia, hypotension, bronchospasm/bronchial hyperresponsiveness, and hypoglycemia. ARs are mild, and ARs that are severely intolerable are very rare (48). However, blood pressure, heart rate, and body temperature should be monitored during drug administration. Existing reports have shown that propranolol has no significant effect on neurodevelopment in children (49); however, close monitoring of the central nervous system and sleeprelated events is still necessary (50). To reduce the systemic ARs caused by oral administration of propranolol, some researchers have developed propranolol cream/gel (51-53), propranolol-loaded liposomes-in-microspheres (54), propranolol-loaded mesoporous silica nanoparticle administrative system (55), and a thin polymeric film system composed of polyvinyl alcohol and acrylic acid polymer for propranolol administration (56). However, further studies on their therapeutic efficacy and safety are necessary.

In addition to propranolol, other $\beta$ blockers have also been used to treat IHs, including atenolol $(57,58)$, nadolol (59), and acebutolol (60). A retrospective study by Graaf et al. (61) comparatively analyzed the results of 30 IH pediatric patients who orally received $1.0 \mathrm{mg} / \mathrm{kg}$ QD atenolol and $28 \mathrm{IH}$ pediatric patients who orally received $2.0 \mathrm{mg} / \mathrm{kg} / \mathrm{d}$ propranolol, and found the same therapeutic efficacy with no serious ARs in both treatment groups. In the study by Ji et al. (62), 70 children with proliferating IHs were administered $1.0 \mathrm{mg} / \mathrm{kg}$ QD oral atenolol for a 24-week treatment. The results showed that the IHs stopped growing in $93.4 \%$ of children after 4 weeks of treatment, and $56.5 \%$ were cured or nearly cured after 24 weeks of treatment. These children had no serious ARs during treatment, but some mild and common ARs, including diarrhea, agitation, and sleep disorders. Abarzua-Araya et al. (63) conducted a randomized controlled trial to compare the therapeutic efficacies of atenolol and propranolol for IH treatment and proved quite effective outcomes in the two-drug treatment groups. Pope et al. (64) conducted a blinded study of oral nadolol and propranolol and gave $4.0 \mathrm{mg} / \mathrm{kg}$ QD nadolol orally to $10 \mathrm{IH}$ infants and $2.0-3.0 \mathrm{mg} / \mathrm{kg} / \mathrm{d}$ propranolol (divided into three oral administrations) to nine IH infants. The results showed that the therapeutic effect of nadolol was better than that of propranolol. These studies all showed that $\beta$ blockers are effective in treating IHs. The $\beta 1$ receptor 
is abundantly expressed in the proliferative phase of IHs (65). Atenolol and acebutolol are selective $\beta$ blockers, and proper concentrations of these drugs can selectively act on $\beta 1$ receptors to enhance their therapeutic effects and prevent ARs caused by other $\beta$ receptors. Also, the lipid solubility of atenolol and acebutolol is lower than that of propranolol, and these drugs do not penetrate the blood-brain barrier and enter the brain easily. Their concentrations in the cerebrospinal fluid are low, which hardly affects the central nervous system in patients.

\section{Glucocorticoids}

Before the application of propranolol for IH treatment, glucocorticoids, as first-line therapeutic drugs for $\mathrm{IH}$, have a certain value for the treatment of refractory and complicated IHs. Glucocorticoids are used in contraindications to $\beta$ blockers and cases with no therapeutic response to $\beta$ blockers. The common prednisone dosage is $2-3 \mathrm{mg} / \mathrm{kg} / \mathrm{d}$ for 4-12 weeks of treatment, followed by gradually reducing the dosage, with treatment lasting until patients are $9-12$ months old $(7,66,67)$. The recommended dosage in China is $3-5 \mathrm{mg} / \mathrm{kg}(\leq 50 \mathrm{mg}$ total dose) prednisone tablets once every morning for eight consecutive weeks, followed by reducing half of the dose at week 9, using $10 \mathrm{mg}$ per treatment at week $10,5 \mathrm{mg}$ per treatment at week 11, and completing a course of treatment at week 12 . The same course of treatment can be repeated after 4-6 weeks if necessary, which usually takes several months or more. Because sudden withdrawal or rapid reduction in glucocorticoid dosage may cause a rebound, the dosage of treatment should be tapered off before discontinuation. The therapeutic mechanisms of glucocorticoids $(68,69)$ include downregulation of VEGF- $\alpha$ in vivo; inhibition of monocyte chemotactic protein 1, interleukin (IL)-6, MMP-1, and urokinase-type plasminogen activator receptor; inhibition of NF- $\mathrm{\kappa B}$ activity; and antagonizing the effect of estrogen. Long-term consumption of glucocorticoids may cause some ARs including Cushing syndrome, secondary infection, affecting growth and development, gastrointestinal discomfort (e.g., nausea, vomiting, ulcers, and diarrhea), mental symptoms (e.g., agitation, insomnia, and feeling down), and adrenal suppression.

\section{Renin-angiotensin system (RAS)-acting drugs}

The role of the RAS in the proliferation of endothelial cells in hemangioma has been confirmed in recent years $(12,70)$. Angiotensin-converting enzyme inhibitors have been used for the treatment of IHs. Tan et al. (71) treated eight IHs with captopril orally at a dosage of $0.5 \mathrm{mg} / \mathrm{kg} \mathrm{q} 8 \mathrm{~h}$, including seven cases treated for 14 months, and the other treatment duration was 12.5 months. A significant response was found in all infants during the 8-19-month follow-up, with three cases of significant responses, two cases of moderate responses, and three cases of slow responses. The IHs resolved continuously, and one patient had transient mild renal damage. No other ARs were observed. A retrospective analysis of Christou et al. (72) showed that $17 \mathrm{IH}$ children developed hypertension due to glucocorticoid. They were then treated with captopril. After the additional captopril treatment, the children with IHs had no improvement. However, the average time of captopril monotherapy in the study of Christou et al. was only 3 weeks, and a drug interaction between captopril and steroids cannot be ruled out. Zaher et al. (73) completed a randomized controlled trial to compare the therapeutic efficacy of propranolol and captopril in IHs. A total of $15 \mathrm{IH}$ children were given $2.0 \mathrm{mg} / \mathrm{kg} / \mathrm{d}$ propranolol orally (divided into two administrations) for 6-12 months and another $15 \mathrm{IH}$ children were given $0.5-1.0 \mathrm{mg} / \mathrm{kg} / \mathrm{d}$ captopril orally for $8-13$ months. The results showed that the captopril treatment group had some therapeutic effects, but the effects were less pronounced than those with propranolol, and four patients in the captopril treatment group had ARs such as hypotension or dizziness. Another study showed that Ramipril and angiotensin II receptor blockers inhibited the proliferation of IH tissue cultured in vitro (74), suggesting that RAS-acting drugs have potential value in IH treatment. However, further studies on their therapeutic efficacy and safety are necessary.

\section{Itraconazole}

In 2015, Ran et al. (75) reported the successful treatment of IHs with itraconazole in the first two infants to receive oral itraconazole due to IH complicated with ulcers and fungal infections. The ulcers were healed, and the IH was cured. Subsequently, four IH infants (without ulcer and fungal infection) were treated with $5.0 \mathrm{mg} / \mathrm{kg} / \mathrm{d}(20-50 \mathrm{mg} / \mathrm{d})$ itraconazole orally for 2-9 weeks with a 3-19-month follow-up. In the first month, the IH lesions changed from reddish to pinkish color, and all IHs stopped growing. At the last follow-up, four cases had an $80-100 \%$ improvement of $\mathrm{IH}$ color and size, indicating obvious therapeutic efficacy. Mild diarrhea was found in two cases, and the remaining cases had no ARs. This research group reported another IH case in 2017 in a 3-month-old infant (76), who was treated with a topical wet compress of timolol maleate ophthalmic solution (twice a day, 1 hour each time, approximately $0.5 \mathrm{~mL}$ per treatment) and showed no curative effect, followed by replacing the treatment to oral itraconazole 
solution $(5.0 \mathrm{mg} / \mathrm{kg} / \mathrm{d})$. During the new treatment, the skin lesion color was gradually darkened. After 68 days, clinical and dermoscopic observations showed obvious signs of regression of the hemangioma. After 4 months, the hemangioma was resolved, and a small amount of fibrous adipose tissue was left although the specific mechanism was unclarified. However, as early as 2007, some researchers (77) have shown that itraconazole inhibits the growth of endothelial cells in the G1 phase and blocks VEGF/FGFdependent angiogenesis. Also, 14 alpha-demethylase $(14 \mathrm{DM})$ is required for endothelial cell proliferation and is the target of itraconazole. Itraconazole may prevent vascular proliferation by inhibiting 14DM action. Chen et al. (78) studied the inhibitory effects of itraconazole on IHs in mouse vascular endothelial cells and primary endothelial cells derived from IHs and the underlying molecular mechanisms. The results showed that itraconazole inhibited the expression of PDGF D and its downstream phosphatidylinositol 3-kinase/Akt/rapamycin target signals, which play important roles in IH pathogenesis. Few studies on IH treatment with itraconazole have been reported, and there is a lack of large-scale clinical research to study the therapeutic efficacy and safety of itraconazole, which needs further investigations.

\section{Curcumin}

Curcumin is a chemical component extracted from the rhizome of turmeric. It has a variety of biological activities such as anti-inflammatory, anti-oxidation, anti-coagulation, and anti-tumor effects. Thus, it has been widely used for the prevention and treatment of various diseases. In addition to being used as a drug in clinical practice, curcumin is also used as a food additive and as a natural food coloring because it is safe. An earlier study showed that curcumin inhibits endothelial cell proliferation and FGF-mediated corneal neovascularization in mice, indicating that it has direct anti-angiogenic activity in vitro and in vivo (79). Hassell et al. (80) used $400 \mathrm{mg} / \mathrm{d}$ oral curcumin for 9 months to successfully cure infantile hemangioendothelioma in the liver of a 6-month-old infant. Lou et al. (81) used curcumin to react with endothelial cells in $\mathrm{IH}$ and observed the changes in cell proliferation and apoptotic signaling pathways. The results showed that curcumin inhibited the expression of anti-apoptotic protein myeloid cell leukemia-1, HIF-1 $\alpha$, and VEGF, thereby inducing apoptosis and inhibiting the proliferation of endothelial cells in IHs. Currently, no reports on curcumin for IH treatment are available. Therefore, further studies are necessary to verify if curcumin, as a highly safe drug, also has beneficial effects on IH treatment, which would provide a safer and more effective choice for the treatment of this disease.

\section{Topical medications Topical $\beta$ blockers}

With the application of $\beta$ blockers in IH treatment, topical $\beta$ blockers have quickly gained attention. Theoretically, topical $\beta$ blockers only act locally on lesions, but do not enter the systemic circulation and are more effective and safer than oral beta blockers for IH treatment, especially for superficial IH. The used topical $\beta$ blockers include propranolol gel (cream), timolol eye drops (hydrogel), and carteolol drops. There have been many studies on timolol, and several studies have used timolol maleate ophthalmic solution and homemade timolol gel to treat IHs, involving more than 1,000 patients (82-89). Puttgen et al. (88) completed a multicenter retrospective cohort study at nine centers to study $731 \mathrm{IH}$ patients who were administered topical timolol. The results showed that timolol is a welltolerated and safe treatment for IH, especially for superficial $\mathrm{IH}$, with good therapeutic efficacy. Wu et al. (87) compared the difference between topical timolol and oral propranolol in IH treatment. A total of $724 \mathrm{IH}$ infants were included in the study with $362 \mathrm{IH}$ infants receiving $2.0 \mathrm{mg} / \mathrm{kg} / \mathrm{d}$ oral propranolol, divided into two oral administrations, and another $362 \mathrm{IH}$ infants receiving $0.5 \%$ timolol hydrogel treatment three times a day by applying a thin layer of timolol hydrogel on the entire lesion surface of IH for 6-7 months. These patients were followed up for 6.5 months. The results showed that topical timolol and oral propranolol had the same effects on superficial IH and reduced the risk of systemic ARs. Another meta-analysis of 887 children with IH in 10 studies (including retrospective studies, prospective cohort studies, and randomized controlled trials) (86) showed that topical timolol treatment had better therapeutic efficacy and less ARs than laser therapy, placebo therapy, and observation. No significant difference in therapeutic efficacy was found between topical timolol and oral propranolol treatments. A systematic review (90) also indicated that topical timolol therapy had the same therapeutic efficacy as oral propranolol treatment with and few ARs.

Many studies on topical propranolol are available. Price et al. (91) conducted a systematic review that included 12 studies and a total of $597 \mathrm{IH}$ pediatric patients who were treated with $0.5-5 \%$ homemade propranolol gel, cream, and ointment. The results indicated that topical propranolol is effective and safe for the treatment of superficial IH. Mashiah 
et al. (92) retrospectively analyzed $75 \mathrm{IH}$ cases treated with propranolol gel (4\% propranolol gel, $150 \mathrm{mg} / 5 \mathrm{~cm}^{2}$ on the lesion area, twice a day for 5-9 months). The results showed that 43 had a good response to treatment; 19 had a partial response; 13 had no response to treatment; 2 patients developed mild local side effects, showing irritation and redness; and the remaining IH children had no other observed ARs. Zhai et al. (93) treated $51 \mathrm{IH}$ children with $3 \%$ propranolol gel 3-4 times/d by evenly applying the gel on the lesion surface. The Achauer system was used to evaluate the therapeutic efficacy of the topical propranolol medication in the 1-10-month follow-up. Patients with grade I reaction (poor) accounted for $17.24 \%$, those with grade II reaction (moderate) accounted for $24.14 \%$, those with grade III reaction (good) accounted for $44.83 \%$, and those with grade IV reaction (excellent) accounted for $13.79 \%$. Two IH cases with reddish lesion areas and one case with rash around the lesion resolved spontaneously, suggesting that topical use of $3 \%$ propranolol gel is effective for the treatment of superficial hemangioma. Gan et al. (94) conducted a prospective study of topical carteolol for the treatment of superficial IH. A total of 349 infants were included in the study and randomly divided into two groups: the treatment group $(\mathrm{n}=224)$ with $2 \%$ carteolol hydrochloride drops twice a day for 6 months of treatment; the observation group $(\mathrm{n}=125)$ with no drug treatment. The results showed that among infants with carteolol treatment, 24 cases responded well, 162 cases had partial remission, and 38 cases had no response. In the observation group, 7 cases had remission, 32 cases had partial remission, and 86 cases had no remission. No ARs were observed during the treatment period, suggesting that $2 \%$ carteolol hydrochloride drops are an effective and safe topical IH treatment.

Usage and dosage: In China, commercially available $0.5 \%$ timolol maleate eye drops three times a day (6-8 h apart) is recommended. It is used by dropping the ophthalmic solution on absorbent cotton or one to two layers of gauze $\left(30-40 \mu \mathrm{L} / \mathrm{cm}^{2}\right)$ to evenly soak the cotton or gauze, and applying to the lesion surface for $5-15 \mathrm{~min}$, with the cotton or gauze, keeping it moist (95). Others also smear $0.25 \%$ or $0.5 \%$ timolol gel on the IH lesion two to three times a day, $3 \%$ propranolol gel on the IH lesion two to three times a day, or $2 \%$ carteolol hydrochloride drops twice a day. Because no topical $\beta$ blocker for IH is currently commercially available, caution should be exercised when using it off label or as a research product. Common ARs include itching, dry skin, peeling skin, rash, and angioedema.

\section{Imiquimod}

Before the initiation of $\beta$ blockers for IH treatment, $5 \%$ imiquimod cream was used for the treatment of superficial IH and achieved good therapeutic outcomes (96-98). Studies $(99,100)$ have shown that after imiquimod treatment, the cell proliferation of hemangioma decreased and apoptosis increased, the expression of TIMP-1 increased, and the expression of MMP-9 decreased. With the use of imiquimod in clinical practice, severe local irritation such as erythema and even scar formation may occur (101). After $\beta$ blockers were used externally to treat IHs, the administration of imiquimod was reduced. Studies comparing the therapeutic efficacy and safety between timolol and imiquimod have shown that timolol is more effective and has fewer adverse effects $(83,102)$. Thus, it is recommended that $5 \%$ imiquimod be used in $\mathrm{IH}$ children with contraindications for topical $\beta$ blockers by applying a thin layer of $5 \%$ imiquimod to the lesion surface every other night before going to bed and washing off the imiquimod the next day for 16 weeks of treatment.

\section{Injectable medications \\ Injectable medications applied topically}

Local injection of the drug for the treatment of IH has a precise range of action, with the characteristics of high local dosage and less systemic ARs. However, some topical injectable medications may also cause strong irritation, and some antitumor drugs (e.g., bleomycin and pingyangmycin) are cytotoxic. Overdose or injection of these medications into normal tissues may cause cell damage. Locally injected drugs are suitable for the treatment of early-stage, localized, deep, or thickened hemangioma and include bleomycin, glucocorticoids, lauromacrogol, and urea.

Bleomycin is an antitumor antibiotic that interferes with cell division and proliferation by preventing DNA replication. Pingyangmycin has similar components of bleomycin and the same antitumor mechanism. It is used for IH treatment in China by locally injected into the lesion(s). A previous study showed that pingyangmycin promotes the apoptosis of proliferating hemangioma, and its underlying mechanism may be related to blocking the cell cycle and activating the apoptotic signal transduction pathway (103). Studies have confirmed the therapeutic efficacy of pingyangmycin on IHs $(104,105)$. However, another study concluded that local injection of pingyangmycin for the treatment of IH is not safe because it might lead to soft tissue atrophy (106). With the emergence of newer and safer drugs with better therapeutic effects, the value of 
pingyangmycin in IH treatment has gradually decreased. Nevertheless, studies have also confirmed that local bleomycin or pingyangmycin injection is an alternative treatment for IH children with no response or with the residual lesion(s) after propranolol treatment (107-109).

In addition to the oral treatment of IHs, glucocorticoids can also be injected intralesionally, which is effective in long-term applications (110-113). Used glucocorticoids include triamcinolone acetonide and compound formulations of betamethasone $(1 \mathrm{~mL}$ containing $2 \mathrm{mg}$ betamethasone sodium phosphate and $5 \mathrm{mg}$ betamethasone dipropionate) with $2.0-3.0 \mathrm{mg} / \mathrm{kg}$ triamcinolone acetonide and $0.5-2.0 \mathrm{~mL}$ betamethasone via multiple injections at the lesion edge or lesion center, or intralesional injection at a single site. Therapeutic outcomes are evaluated 4-6 weeks later to decide if re-injection is needed. Emir et al. (114) used $2.0 \mathrm{mg} / \mathrm{kg}$ triamcinolone acetonide to locally inject the IHs of six IH children for 1 year, with monthly followup (one case received five administrations, two cases received four administrations, one case received three administrations, and the two remaining cases received two administrations). The results showed that the IH patients developed adrenal suppression after the second or third injection of triamcinolone acetonide. Adrenal suppression was gradually restored to normal after treatment termination. Glucocorticoids have many potential ARs, and the risk of long-term usage is greater in infants and young children. In addition to local side effects, local injection of glucocorticoids causes systemic ARs once the overdose is absorbed in the bloodstream. Thus, it is necessary to administer the local injection of glucocorticoids at an appropriate dosage and treatment course.

Lauromacrogol is a used hardener that is used for the treatment of varicosity. During usage, the local injection of lauromacrogol blocks the blood supply to IHs and destroys vascular endothelial cells, causing embolization of blood vessels and necrosis. Wang et al. (115) intralesionally injected $1 \%$ lauromacrogol in 42 cases of hemangioma and 13 cases of vascular malformation and followed up with these patients for 3-16 months. The results showed 41 cured cases, 9 cured cases, 5 effective cases, and 2 cases of local skin ulceration that was healed after dressing change; no other serious complications were observed. Yu et al. (116) treated $56 \mathrm{IH}$ cases with a local and multi-point injection of lauromacrogol injection once every 4 weeks for no more than 5 months of treatment, followed by 6 months to 2 years follow-up. The results showed that the local and multi-point injection of lauromacrogol injection had
$85.7 \%$ therapeutic efficacy, and local swelling was found at the injection site, which resolved spontaneously. No other ARs were observed. However, lauromacrogol may cause scarring and ulceration during the treatment of IHs, and thus, is not recommended as the primary therapy choice for IH. The use of this therapy is limited to China only, and lauromacrogol is only recommended as adjuvant therapy for hemangiomas.

Urea is also a hardener but is different from other hardeners. Urea is a metabolite of the human body. It has good compatibility with the human body and does not accumulate in the body. It has almost no side effects after entering the body and has been used in China for more than 20 years (117) to treat hemangioma based on the following mechanism: the tissue at the site of hemangioma immediately shows acute sterile inflammation after the urea injection, by shrinking endothelial cells in the hemangioma and causing degeneration, necrosis, and fibrosis in the lesion(s) (118). To reduce the number of administrations and enhance therapeutic efficacy, Zhu et al. (117) developed urea-loaded liposomes in microspheres to show their significant therapeutic efficacy on IH in animal models. The number of administrations was reduced by persistent release in the model. Also, this treatment inhibited the proliferation of hemangioma endothelial cells (HemECs) and expression of VEGF-A and HIF- $1 \alpha$ in HemECs. Only a few reports on $\mathrm{IH}$ treatment with urea alone have been published, most of which was adjunct to other therapies such as in combination with propranolol, pingyangmycin, and surgical treatment of some hemangioma localized at special sites. This IH treatment is limited to use in China.

\section{Injectable medications applied systemically}

Injectable medications applied systemically for IH treatment include vincristine and interferon. Vincristine has the effect of promoting apoptosis of vascular endothelial cells and tumor cells. Studies have confirmed that the application of vincristine in IH treatment of critically ill patients (119) and children with glucocorticoid resistance (dependent) $(120,121)$ demonstrates good therapeutic efficacy. However, with the emergence of new, safer, and more effective therapies, vincristine has been rarely used to treat IHs, considering some serious side effects of systemic antitumor drugs including neurotoxicity, myelosuppression, leukopenia, and anemia. Vincristine is currently and used for borderline or malignant hemangioma such as hemangioendothelioma.

Interferon has antiviral and antitumor effects. A previous study showed that interferon inhibits the proliferation 
of hemangiomas and promotes apoptosis (122). Chang et al. (123) showed the successful treatment of four IH children using interferon-alpha-2b. Zhang et al. (124) also used interferon-alpha-2a to successfully treat $11 \mathrm{IH}$ patients who had no response to propranolol and hormonal therapies. Damas et al. (125) retrospectively analyzed four IH children with interferon therapy ( 3 million $\mathrm{U} / \mathrm{m}^{2}$ interferon-alpha$2 \mathrm{~b}$ subcutaneous injection once a day for $\geq 3.5$ months), and showed that three patients had hemangioma volume reduced by $95 \%$; the remaining cases had hemangioma volume reduced by $>50 \%$. One case was found to have spastic diplegia. No persistent neurological dysfunction was found after stopping the treatment. Another case had dyslipidemia. Damas et al. concluded that interferon was effective for IH treatment, but its ARs might be severe. A meta-analysis of hemangioma treated with interferon showed that interferon therapy causes serious ARs (126). This meta-analysis included 391 children with hemangioma and showed that $2.8 \%$ of the patients had spastic diplegia and $4.1 \%$ of the patients had complications in motor development such as deep tendon hyperreflexia, gait disturbances, and fine motor impairment. These complications were gradually alleviated after discontinuation of interferon. Therefore, it is not recommended that interferon be used in infants under 1 year of age unless the IH is life-threatening and other treatment options are not effective. For children with critical illness and ineffective outcomes using other treatment options, interferon therapy may be an effective therapeutic option $(127,128)$. However, further studies are necessary to determine its safety and effectiveness.

\section{Potential therapeutic drugs}

With the study of the pathogenesis of IHs, many potential therapeutic targets (substances) have been discovered (see Table 1 for details). The development of therapeutic drugs, according to these targets, will offer more options for the treatment of IHs.

Studies have confirmed that the RAS plays a role in the pathological process of IHs. Cathepsin B promotes the production of renin, thereby promoting the production of angiotensin; cathepsin D promotes the conversion of angiotensinogen to angiotensin I, and cathepsin $\mathrm{G}$ promotes the conversion of angiotensin I to angiotensin II and the direct conversion of angiotensinogen to angiotensin II. The development of drugs targeting cathepsins B, D, and $G$ may block the production of angiotensin and exert antiangiogenic effects. There are also studies on angiotensinconverting enzyme inhibitors and angiotensin II receptor blockers, which play roles in the treatment of IHs through these two pathways.

\section{Surgical treatment}

Propranolol is currently considered first-line treatment for IHs. However, for some IH children with vascular malformations and skin scars and even ineffective outcomes and relapse after drug treatment, surgical resection may be an alternative treatment because of its short treatment period, rapid lesion removal, and significant improvement in the appearance of the lesion site. Cheng et al. (140) conducted a quantitative analysis of the incidence of complications and adverse events in 1,180 IH children (median age, 3.2 years) with surgical resection of the hemangiomas. The results suggested that surgical resection may be a safe treatment approach for patients with ineffective outcomes and incomplete treatment. IH children over 3 years of age had fewer surgical adverse events than those less than 3 years of age. In general, the incidence of surgical resection of IHs is low. Also, surgical resection can be performed in some high-risk IH cases such as IHs that cause organ dysfunction, IHs accompanied by hemorrhage and IHs localized in the scalp (141).

\section{Laser therapy}

The laser selectively acts on the chromophore in IHs with oxygen-containing hemoglobin being predominant. The chromophore absorbs light to heat the lesion and causes coagulation, thereby exerting therapeutic effects $(142,143)$. It is suitable for superficial, naturally regressed, and residual IHs after drug treatment(s) (144). However, different lasers have different scopes of application, and pulsed dye laser (PDL), Nd:YAG laser, and fractional carbon dioxide laser is used for the treatment of IHs.

PDL has mostly been reported and applied in IH laser therapy (144), with the common parameters of 585-595 nm wavelength, $0.45-40 \mathrm{~ms}$ pulse width, $2-12 \mathrm{~mm}$ spot size, and $3-15 \mathrm{~J} / \mathrm{cm}^{2}$ energy density. It has been used for treating small IH lesions at an early stage and quickly resolves the residual lesion in the regressive phase. Longpulsed PDL has a higher success rate in treating IH due to its advantage in transdermal depth (144). In a previous study, IH children had a higher incidence of adverse effects such as skin atrophy and hyperpigmentation after PDL therapy (145). PDL technology with a cooling function has been proposed to lower the incidence of the 
Table 1 Potential therapeutic targets/drugs

\begin{tabular}{|c|c|c|c|}
\hline Literature & Research methods & Target/drug & Mechanisms \\
\hline Li et al. (131) & $\begin{array}{l}\text { In vitro, immunohistochemistry, } \\
\text { quantitative RT-PCR }\end{array}$ & PEDF & $\begin{array}{l}\text { PEDF expression was increased during the } \mathrm{IH} \text { regression } \\
\text { phase and may have effects on promoting } \mathrm{IH} \text { regression }\end{array}$ \\
\hline $\begin{array}{l}\text { Itinteang et al. } \\
\text { (132) }\end{array}$ & $\begin{array}{l}\text { In vitro, immunohistochemistry, } \\
\text { enzyme activity assays, mass } \\
\text { spectrometry, and Nano String } \\
\text { gene expression assay }\end{array}$ & Cathepsins B, D, G & $\begin{array}{l}\text { The expression of cathepsins } \mathrm{B}, \mathrm{D} \text {, and } \mathrm{G} \text { was detected in } \\
\text { various stages of IHs. Cathepsin B promoted the production } \\
\text { of renin; cathepsin D induced the production of angiotensin } \\
\text { I, and cathepsin G induced the conversion of angiotensin I to } \\
\text { angiotensin II (Figure 1) }\end{array}$ \\
\hline $\begin{array}{l}\text { Chisholm et al. } \\
\text { (133); Dal et al. } \\
\text { (134) }\end{array}$ & $\begin{array}{l}\text { In vitro, histochemistry, } \\
\text { immunohistochemistry, } \\
\text { enzyme-linked immunosorbent } \\
\text { assay, and colorimetry }\end{array}$ & $\beta 3$-adrenergic receptor & $\begin{array}{l}\text { the } \beta 3 \text {-adrenergic receptor was highly expressed in various } \\
\text { stages of IHs and played a role in the pathogenesis of IHs, } \\
\text { stimulating the release of VEGF and affecting various } \\
\text { intracellular pathways and vascular functions }\end{array}$ \\
\hline $\begin{array}{l}\text { Amaya et al. } \\
(135)\end{array}$ & $\begin{array}{l}\text { In vitro, histochemistry, and } \\
\text { immunohistochemistry }\end{array}$ & $\begin{array}{l}\text { Programmed cell death } \\
\text { protein-1 (PD-1) }\end{array}$ & $\begin{array}{l}\text { Programmed cell death protein } 1 \text { was highly expressed } \\
\text { in endothelial cells, whereas expression of programmed } \\
\text { death-ligand } 1 \text { was negative in six IH cases, which provided } \\
\text { the possibility for immunotherapy }\end{array}$ \\
\hline Cai et al. (136) & In vivo, in vitro & 15,16-dihydrotanshinone I & $\begin{array}{l}\text { Increased expression of apoptosis-associated proteins and } \\
\text { significantly inhibited angiogenesis. In vivo experiments } \\
\text { showed significant inhibition of hemangiomas }\end{array}$ \\
\hline
\end{tabular}

PEDF, pigment epithelium-derived factor; Linc00152, a long non-coding RNA; UCA1, urothelial carcinoma associated 1.

abovementioned adverse effects. A randomized controlled trial (146) and retrospective study (147) demonstrated that $595 \mathrm{~nm}$ PDL with a cooling function has better therapeutic effects, causing fewer pigmentation abnormalities and a lower risk of skin texture changes after treatment. Studies $(148,149)$ have shown that PDL combined with $\beta$ blocker treatment has better therapeutic efficacy and shorter recovery time in IH treatment compared with
PDL monotherapy. Therefore, application of long-pulse PDL with a cooling system is a safer IH treatment. PDL combined with propranolol, or other $\beta$ blockers may have better therapeutic outcomes; however, the adverse events caused by these therapies should be considered including common adverse events such as local edema and pain and extremely rare adverse events including severe pain, permanent scarring, and ulceration with bleeding (150). 


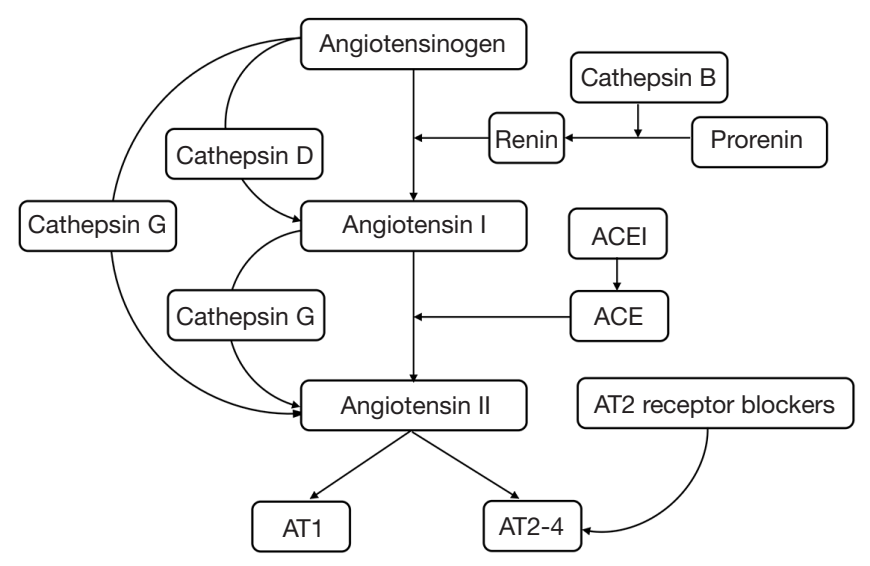

Figure 1 Mechanism of cathepsins B, D, and G in the renin-angiotensin system. ACE, angiotensin-converting enzyme; ACEI, angiotensinconverting enzyme inhibitors; AT, angiotensin receptor.

$\mathrm{Nd}$ :YAG laser is an infrared laser with a wavelength of $1,064 \mathrm{~nm}$ that is poorly absorbed by oxygenated hemoglobin, but can penetrate deeply into the skin, showing good therapeutic effects on thick tumors (151). Nd:YAG laser therapy is divided into two categories according to the mode of energy output: continuous Nd:YAG laser and pulse Nd:YAG laser. Continuous Nd:YAG laser is suitable for mucosal hemangioma. When used for IH in the skin, excess energy may damage the surrounding normal tissue and leave scars. Another study (152) suggested that Nd:YAG laser therapy should be cautiously used on thick IH. Pulse Nd:YAG laser therapy shows better therapeutic outcomes and safety compared with continuous Nd:YAG laser therapy and penetrates deeper compared than PDL therapy.

The fractional $\mathrm{CO}_{2}$ laser, belonging to the fractional laser, has strong transmission ability and can deeply penetrate the dermis. It has exfoliation effects and can promote epidermal regeneration, achieving skin surface reconstruction with short recovery time. It can be used to treat fibrofatty residual and atrophic plaques after the regression of hemangioma (153). Brightman et al. (154) applied the ablative fractional $\mathrm{CO}_{2}$ laser to treat the fibrofatty residual of five children after the regression of hemangioma. The laser therapy improved the fibrofatty residual by at least $50-75 \%$ in the five patients, who had an obvious improvement in color, texture, and overall appearance.

\section{Observation}

Because most IHs can resolve spontaneously in IH children 1 year of age or older, continuous observation of some simple and localized hemangioma without risk factors is feasible by monitoring the growth and regression of IHs. For example, continuously photographing the lesions to compare the changes of IHs, and follow-up assessment regularly in the hospital can be conducted. Through continuous observations, it is possible to avoid the occurrence of unfavorable conditions and provide physicians with information on lesion changes.

\section{Summary}

Oral propranolol is currently the first-line treatment for IHs. With the accumulation of clinical studies, propranolol topical treatment, or other $\beta$ blocker therapies have good application prospects for the treatment of this disease. Many candidate treatments for IHs are available. When first-line treatment becomes ineffective or contraindicated, glucocorticoids therapy, local injection of the drug, and surgical resection can be considered. For residual lesions in the IH regression phase, laser therapy helps children with IH rapidly recover and improve their appearance. The discovery of potential therapeutic targets and the development of new drugs will provide more choices for the treatment of IHs.

\section{Acknowledgments}

Funding: This work was supported by the National Natural Science Foundation of China (No. 81602699 to ZY He), the Sichuan Science and Technology Program (Nos. 2018GZ0311 to T Xu, 2019YFG0266 to ZY He), the 
National High Technology Research and Development Program of China (No. 2015AA020309 to ZY He), the Health Commission of Sichuan Province (No. 18PJ543 to $\mathrm{ZY} \mathrm{He}$ ), the Salubris Academician Workstation for Innovative Biopharmaceuticals (No. 2017B090904017 to $\mathrm{ZY} \mathrm{He}$ ), and the 1.3.5 project for disciplines of excellence, West China Hospital, Sichuan University (No. ZYJC18028 to $\mathrm{T} \mathrm{Xu}$ ).

\section{Footnote}

Conflicts of Interest: The authors have no conflicts of interest to declare.

Ethical Statement: The authors are accountable for all aspects of the work in ensuring that questions related to the accuracy or integrity of any part of the work are appropriately investigated and resolved.

\section{References}

1. Munden A, Butschek R, Tom WL, et al. Prospective study of infantile haemangiomas: incidence, clinical characteristics and association with placental anomalies. $\mathrm{Br}$ J Dermatol 2014;170:907-13.

2. Dickison P, Christou E, Wargon O. A prospective study of infantile hemangiomas with a focus on incidence and risk factors. Pediatr Dermatol 2011;28:663-9.

3. Frieden IJ, Haggstrom AN, Drolet BA, et al. Infantile hemangiomas: current knowledge, future directions. Pediatr Dermatol 2005;22:383-406.

4. Cazeau C, Blei F, Gonzales Hermosa M, et al. Burden of infantile hemangioma on family: an international observational cross-sectional study. Pediatr Dermatol 2017;34:295-302.

5. Haggstrom AN, Drolet BA, Baselga E, et al. Prospective study of infantile hemangiomas: demographic, prenatal, and perinatal characteristics. J Pediatr 2007;150:291-4.

6. Léauté-Labrèze C, Harper JI, Hoeger PH. Infantile haemangioma. Lancet 2017;390:85-94.

7. Krowchuk DP, Frieden IJ, Mancini AJ, et al. Clinical practice guideline for the management of infantile hemangiomas. Pediatrics 2019;143:e20183475.

8. Hoeger PH, Harper JI, Baselga E, et al. Treatment of infantile haemangiomas: recommendations of a european expert group. Eur J Pediatr 2015;174:855-65.

9. Yin RR, Hao D, Chen P. Expression and correlation of MMP-9, VEGF, and p16 in infantile hemangioma. Eur
Rev Med Pharmacol Sci 2018;22:4806-11.

10. Oszajca K, Szemraj J, Wyrzykowski D, et al. Singlenucleotide polymorphisms of VEGF-A and VEGFR-2 genes and risk of infantile hemangioma. Int J Dermatol 2018;57:1201-7.

11. Ji Y, Chen S, Li K, et al. Signaling pathways in the development of infantile hemangioma. J Hematol Oncol 2014;7:13.

12. Itinteang $\mathrm{T}$, Withers $\mathrm{AH}$, Davis PF, et al. Biology of infantile hemangioma. Front Surg 2014;1:38.

13. Takahashi K, Mulliken JB, Kozakewich HPW, et al. Cellular markers that distinguish the phases of hemangioma during infancy and childhood. J Clin Invest 1994;93:2357-64.

14. de Jong S, Itinteang T, Withers AH, et al. Does hypoxia play a role in infantile hemangioma? Arch Dermatol Res 2016;308:219-27.

15. Kleinman ME, Greives MR, Churgin SS, et al. Hypoxiainduced mediators of stem/progenitor cell trafficking are increased in children with hemangioma. Arterioscler Thromb Vasc Biol 2007;27:2664-70.

16. Maclellan RA, Vivero MP, Purcell P, et al. Expression of follicle-stimulating hormone receptor in vascular anomalies. Plast Reconstr Surg 2014;133:344e-51e.

17. Maclellan RA, Konczyk DJ, Goss JA, et al. Analysis of follicle-stimulating hormone receptor in infantile hemangioma. Ann Plast Surg 2018;80:S211-3.

18. Alam H, Weck J, Maizels E, et al. Role of the phosphatidylinositol-3-kinase and extracellular regulated kinase pathways in the induction of hypoxia-inducible factor (HIF)-1 activity and the HIF-1 target vascular endothelial growth factor in ovarian granulosa cells in response to follicle-stimulating hormone. Endocrinology 2009;150:915-28.

19. Radu A, Pichon C, Camparo P, et al. Expression of folliclestimulating hormone receptor in tumor blood vessels. New Engl J Med 2010;363:1621-30.

20. ISSVA classification for vascular anomalies [Internet]. [cited 2019 Sep 25]. Available online: http://www.issva.org/ UserFiles/file/ISSVA-Classification-2018.

21. Hand JL, Frieden IJ. Vascular birthmarks of infancy: resolving nosologic confusion. Am J Med Genet 2002;108:257-64.

22. Léauté-Labrèze C, Dumas de la Roque $\mathrm{E}$, Hubiche T, et al. Propranolol for severe hemangiomas of infancy. New Engl J Med 2008;358:2649-51.

23. Chang L, Ye X, Qiu Y, et al. Is propranolol safe and effective for outpatient use for infantile hemangioma? a 
prospective study of 679 cases from one center in china. Ann Plast Surg 2016;76:559-63.

24. Lahrichi A, Hali F, Baline K, et al. Effects of propranolol therapy in moroccan children with infantile hemangioma. Arch Pediatr 2018;25:449-51.

25. Léauté-Labrèze $\mathrm{C}$, Hoeger $\mathrm{P}$, Mazereeuw-Hautier $\mathrm{J}$, et al. A randomized, controlled trial of oral propranolol in infantile hemangioma. N Engl J Med 2015;372:735-46.

26. Kim KH, Choi TH, Choi Y, et al. Comparison of efficacy and safety between propranolol and steroid for infantile hemangioma: a randomized clinical trial. JAMA Dermatol 2017;153:529-36.

27. Zhang L, Wu HW, Yuan W, et al. Propranolol therapy for infantile hemangioma: our experience. Drug Des Devel Ther 2017;11:1401-8.

28. Xu MN, Zhang M, Xu Y, et al. Individualized treatment for infantile hemangioma. J Craniofac Surg 2018;29:1876-9.

29. Li L, Wei L, Xu ZG, et al. No increased risks associated with propranolol treatment for infantile hemangioma in preterm infants were identified at 3 years of age. Am J Clin Dermatol 2019;20:289-93.

30. Frongia G, Byeon JO, Arnold R, et al. Cardiac diagnostics before oral propranolol therapy in infantile hemangioma: retrospective evaluation of 234 infants. World J Pediatr 2018;14:254-8.

31. Wu C, Guo L, Wang L, et al. Associations between short-term efficacy and clinical characteristics of infantile hemangioma treated by propranolol. Medicine 2019;98:e14346.

32. Stringari G, Barbato G, Zanzucchi M, et al. Propranolol treatment for infantile hemangioma: a case series of sixtytwo patients. Pediatr Med Chir 2016;38:113.

33. Baselga E, Dembowska-Baginska B, Przewratil P, et al. Efficacy of propranolol between 6 and 12 months of age in high-risk infantile hemangioma. Pediatrics 2018;142:e20173866.

34. Kim J, Hong JW, Roh TS, et al. Oral propranolol therapy in 23 infants with infantile hemangioma. Arch Plast Surg 2018;45:517-24.

35. Léaute-Labrèze C, Boccara $\mathrm{O}$, Degrugillier-Chopinet C, et al. Safety of oral propranolol for the treatment of infantile hemangioma: a systematic review. Pediatrics 2016;138:e20160353.

36. Chinnadurai S, Fonnesbeck C, Snyder KM, et al. Pharmacologic interventions for infantile hemangioma: a meta-analysis. Pediatrics 2016;137:e20153896.

37. Solman L, Glover M, Beattie PE, et al. Oral propranolol in the treatment of proliferating infantile haemangiomas: british society for paediatric dermatology consensus guidelines. Br J Dermatol 2018;179:582-9.

38. Smithson SL, Rademaker M, Adams S, et al. Consensus statement for the treatment of infantile haemangiomas with propranolol. Australas J Dermatol 2017;58:155-9.

39. Zheng JW, Wang XK, Qin ZP, et al. Chinese experts consensus on the use of oral propranolol for treatment of infantile hemangiomas. Shanghai Kou Qiang Yi Xue 2016;25:257-60.

40. PDQ ${ }^{\circledR}$ Pediatric treatment editorial board. PDQ Childhood vascular tumors treatment. Bethesda, MD: national cancer institute. Updated $<08 / 15 / 2019>$. Available online: https://www.cancer.gov/types/soft-tissue-sarcoma/ $\mathrm{hp} /$ child-vascular-tumors-treatment-pdq

41. FDA [Internet]. HEMANGEOL ${ }^{\mathrm{TM}}$ (propranolol hydrochloride oral solution) [cited 2019 Sep 25]. Available online: https://www.accessdata.fda.gov/drugsatfda_docs/ label/2014/205410s000lbl.pdf

42. Ji Y, Li K, Xiao XM, et al. Effects of propranolol on the proliferation and apoptosis of hemangioma-derived endothelial cells. J Pediatr Surg 2012;47:2216-23.

43. Sharifpanah F, Saliu F, Bekhite MM, et al. Beta-adrenergic receptor antagonists inhibit vasculogenesis of embryonic stem cells by downregulation of nitric oxide generation and interference with VEGF signalling. Cell Tissue Res 2014;358:443-52.

44. Ma X, Zhao T, Ouyang T, et al. Propranolol enhanced adipogenesis instead of induction of apoptosis of hemangiomas stem cells. Int J Clin Exp Pathol 2014;7:3809-17.

45. Zhang K, Wang F, Huang J, et al. Insulin-like growth factor 2 promotes the adipogenesis of hemangiomaderived stem cells. Exp Ther Med 2019;17:1663-69.

46. Xu W, Li S, Yu F, et al. Role of thrombospondin-1 and nuclear factor-kappaB signaling pathways in antiangiogenesis of infantile hemangioma. Plast Reconstr Surg 2018;142:310e-21e.

47. Burkey BW, Jacobs JA, Aziz H. Temperature instability in an infant treated with propranolol for infantile hemangioma. J Pediatr Pharmacol Ther 2017;22:124-7.

48. Ji Y, Chen S, Wang Q, et al. Intolerable side effects during propranolol therapy for infantile hemangioma: frequency, risk factors and management. Sci Rep 2018;8:4264.

49. Wang C, Wang Q, Xiang B, et al. Effects of propranolol on neurodevelopmental outcomes in patients with infantile hemangioma: a case-control study. Biomed Res Int 2018;2018:5821369. 
50. Thai T, Wang CY, Chang CY, et al. Central nervous system effects of oral propranolol for infantile hemangioma: a systematic review and meta-analysis. J Clin Med 2019;8:E268.

51. Zhou W, He S, Yang Y, et al. Formulation, characterization and clinical evaluation of propranolol hydrochloride gel for transdermal treatment of superficial infantile hemangioma. Drug Dev Ind Pharm 2015;41:1109-19.

52. Shuming C, Shaoquan C, Zaizhong Z, et al. Effects of topical propranolol hydrochloride gel for treatment of infantile hemangioma in nude mice. Zhonghua Zheng Xing Wai Ke Za Zhi 2015;31:446-50.

53. Qi M, Chen X, Xie HF, et al. Effectiveness of external propranolol gel for treatment of superficial infantile hemangioma. Zhongguo Dang Dai Er Ke Za Zhi 2014;16:860-2.

54. Guo X, Zhu X, Liu D, et al. Continuous delivery of propranolol from liposomes-in-microspheres significantly inhibits infantile hemangioma growth. Int J Nanomedicine 2017;12:6923-36.

55. Wu H, Wang X, Zheng J, et al. Propranolol-loaded mesoporous silica nanoparticles for treatment of infantile hemangiomas. Adv Healthc Mater 2019;8:e1801261.

56. Padula C, Nicoli S, Pescina S, et al. Thin polymeric films for the topical delivery of propranolol. Colloids Surf B Biointerfaces 2019,174:582-6.

57. Wang Q, Xiang B, Chen S, et al. Efficacy and safety of oral atenolol for the treatment of infantile haemangioma: a systematic review. Australas J Dermatol 2019;60:181-5.

58. Gumina ME, Yan AC. Atenolol as an alternative to propranolol for the management of sleep disturbances in the treatment of infantile hemangiomas. Pediatr Dermatol 2019;36:556-7.

59. Giberson M, Hayes R. Infantile hemangioma in a v2 distribution: treatment with nadolol. J Family Med Prim Care 2015;4:135-6.

60. Blanchet C, Nicollas R, Bigorre M, et al. Management of infantile subglottic hemangioma: acebutolol or propranolol? Int J Pediatr Otorhinolaryngol 2010;74:959-61.

61. de Graaf M, Raphael MF, Breugem CC, et al. Treatment of infantile haemangiomas with atenolol: comparison with a historical propranolol group. J Plast Reconstr Aesthet Surg 2013;66:1732-40.

62. Ji Y, Wang Q, Chen S, et al. Oral atenolol therapy for proliferating infantile hemangioma: a prospective study. Medicine 2016;95:e3908.

63. Ábarzúa-Araya A, Navarrete-Dechent CP, Heusser F, et al.
Atenolol versus propranolol for the treatment of infantile hemangiomas: a randomized controlled study. J Am Acad Dermatol 2014;70:1045-9.

64. Pope E, Chakkittakandiyil A, Lara-Corrales I, et al. Expanding the therapeutic repertoire of infantile haemangiomas: cohort-blinded study of oral nadolol compared with propranolol. Br J Dermatol 2013;168:222-4.

65. Phillips JD, Zhang H, Wei T, et al. Expression of betaadrenergic receptor subtypes in proliferative, involuted, and propranolol-responsive infantile hemangiomas. JAMA Facial Plast Surg 2017;19:102-7.

66. Greene AK, Couto RA. Oral prednisolone for infantile hemangioma: efficacy and safety using a standardized treatment protocol. Plast Reconstr Surg 2011;128:743-52.

67. Bennett ML, Fleischer AB Jr, Chamlin SL, et al. Oral corticosteroid use is effective for cutaneous hemangiomas: an evidence-based evaluation. Arch Dermatol 2001;137:1208-13.

68. Greenberger S, Boscolo E, Adini I, et al. Corticosteroid suppression of VEGF-A in infantile hemangioma-derived stem cells. N Engl J Med 2010;362:1005-13.

69. Greenberger S, Bischoff J. Infantile hemangiomamechanism(s) of drug action on a vascular tumor. Cold Spring Harb Perspect Med 2011;1:a006460.

70. Sulzberger L, Baillie R, Itinteang T, et al. Serum levels of renin, angiotensin-converting enzyme and angiotensin II in patients treated by surgical excision, propranolol and captopril for problematic proliferating infantile haemangioma. J Plast Reconstr Aesthet Surg 2016;69:381-6.

71. Tan ST, Itinteang T, Day DJ, et al. Treatment of infantile haemangioma with captopril. Br J Dermatol 2012;167:619-24.

72. Christou EM, Wargon O. Effect of captopril on infantile haemangiomas: a retrospective case series. Australas J Dermatol 2012;53:216-8.

73. Zaher H, Rasheed H, El-Komy MM, et al. Propranolol versus captopril in the treatment of infantile hemangioma (IH): a randomized controlled trial. J Am Acad Dermatol 2016;74:499-505.

74. Itinteang T, Marsh R, Davis PF, et al. Angiotensin II causes cellular proliferation in infantile haemangioma via angiotensin II receptor 2 activation. J Clin Pathol 2015;68:346-50.

75. Ran Y, Chen S, Dai Y, et al. Successful treatment of oral itraconazole for infantile hemangiomas: a case series. J Dermatol 2015;42:202-6. 
76. Ran $Y, X u X$, Ran $X$, et al. A case of infantile hemangioma successfully treated by itraconazole oral solution: dermoscopy monitory the vascular regression. Chin J Derm Venereol 2017;31:45-7.

77. Chong $\mathrm{CR}, \mathrm{Xu} \mathrm{J}, \mathrm{Lu} \mathrm{J}$, et al. Inhibition of angiogenesis by the antifungal drug itraconazole. ACS Chem Biol 2007;2:263-70.

78. Chen S, Zhuang K, Sun K, et al. Itraconazole induces regression of infantile hemangioma via down-regulation of the PDGF-D/PI3K/Akt/mTOR pathway. J Invest Dermatol 2019;139:1574-82.

79. Arbiser JL, Klauber N, Rohan R, et al. Curcumin is an in vivo inhibitor of angiogenesis. Mol Med 1998;4:376-83.

80. Hassell LA, Roanh le D. Potential response to curcumin in infantile hemangioendothelioma of the liver. Pediatr Blood Cancer 2010;55:377-9.

81. Lou S, Wang Y, Yu Z, et al. Curcumin induces apoptosis and inhibits proliferation in infantile hemangioma endothelial cells via downregulation of MCL-1 and HIF1alpha. Medicine 2018;97:e9562.

82. Wu Q, Shi Q, Long J, et al. Usage and efficacy of timolol maleate eye drops in treatment of superficial infantile hemangioma. Zhong Nan Da Xue Xue Bao Yi Xue Ban 2017;42:657-61.

83. Hu L, Huang HZ, Li X, et al. Open-label nonrandomized left-right comparison of imiquimod $5 \%$ ointment and timolol maleate $0.5 \%$ eye drops in the treatment of proliferating superficial infantile hemangioma. Dermatology 2015;230:150-5.

84. Wu HW, Liu C, Wang X, et al. Topical Application of $0.5 \%$ timolol maleate hydrogel for the treatment of superficial infantile hemangioma. Front Oncol 2017;7:137.

85. Danarti R, Ariwibowo L, Radiono S, et al. Topical timolol maleate $0.5 \%$ for infantile hemangioma: its effectiveness compared to ultrapotent topical corticosteroids - a single-center experience of 278 cases. Dermatology 2016;232:566-71.

86. Zheng L, Li Y. Effect of topical timolol on response rate and adverse events in infantile hemangioma: a metaanalysis. Arch Dermatol Res 2018;310:261-9.

87. Wu HW, Wang X, Zhang L, et al. Topical timolol vs oral propranolol for the treatment of superficial infantile hemangiomas. Front Oncol 2018;8:605.

88. Püttgen K, Lucky A, Adams D, et al. Topical timolol maleate treatment of infantile hemangiomas. Pediatrics 2016;138:e20160355.

89. Mannschreck DB, Huang AH, Lie E, et al. Topical timolol as adjunct therapy to shorten oral propranolol therapy for infantile hemangiomas. Pediatr Dermatol 2019;36:283-9.

90. Novoa M, Baselga E, Beltran S, et al. Interventions for infantile haemangiomas of the skin: abridged cochrane systematic review and grade assessments. Br J Dermatol 2019;180:527-33.

91. Price A, Rai S, McLeod RW, et al. Topical propranolol for infantile haemangiomas: a systematic review. J Eur Acad Dermatol Venereol 2018;32:2083-9.

92. Mashiah J, Kutz A, Rabia SH, et al. Assessment of the effectiveness of topical propranolol $4 \%$ gel for infantile hemangiomas. Int J Dermatol 2017;56:148-53.

93. Zhai YN, Song HT, Chen SQ, et al. Effect of propranolol gel on infantile hemangiomas.Zhonghua Zheng Xing Wai Ke Za Zhi 2013;29:25-8.

94. Gan LQ, Wang H, Ni SL, et al. A prospective study of topical carteolol therapy in chinese infants with superficial infantile hemangioma. Pediatr Dermatol 2018;35:121-5.

95. Zheng JW, Wang XK, Jiang CH, et al. Chinese expert consensus on the use of topical timolol maleate treatment of infantile hemangiomas. Shanghai Kou Qiang Yi Xue 2016;25:744-7.

96. Ho NT, Lansang P, Pope E. Topical imiquimod in the treatment of infantile hemangiomas: a retrospective study. J Am Acad Dermatol 2007;56:63-8.

97. Welsh O, Olazaran Z, Gomez M, et al. Treatment of infantile hemangiomas with short-term application of imiquimod 5\% cream. J Am Acad Dermatol 2004;51:639-42.

98. Martinez MI, Sanchez-Carpintero I, North PE, et al. Infantile hemangioma: clinical resolution with 5\% imiquimod cream. Arch Dermatol 2002;138:881-4.

99. Sidbury R, Neuschler N, Neuschler E, et al. Topically applied imiquimod inhibits vascular tumor growth in vivo. J Invest Dermatol 2003;121:1205-9.

100. Rocco R, Alegre N, Pozner R, et al. Selective hemangioma cell dysfunction and apoptosis triggered by in vitro treatment with imiquimod. Toxicol Lett 2018;288:82-8.

101. Qiu Y, Ma G, Lin X, et al. Treating protruding infantile hemangiomas with topical imiquimod $5 \%$ cream caused severe local reactions and disfiguring scars. Pediatr Dermatol 2013;30:342-7.

102. Qiu Y, Ma G, Yang J, et al. Imiquimod 5\% cream versus timolol $0.5 \%$ ophthalmic solution for treating superficial proliferating infantile haemangiomas: a retrospective study. Clin Exp Dermatol 2013;38:845-50.

103.Xu WL, Niu AG, Li SL, et al. Pingyangmycin emulsion inducing apoptosis in infantile proliferating capillary hemangiomas. Zhonghua Zheng Xing Wai Ke Za Zhi 
2006;22:362-4.

104.Luo QF, Zhao FY. The effects of bleomycin A5 on infantile maxillofacial haemangioma. Head Face Med 2011;7:11.

105.Hou J, Wang M, Tang H, et al. Pingyangmycin sclerotherapy for infantile hemangiomas in oral and maxillofacial regions: an evaluation of 66 consecutive patients. Int J Oral Maxillofac Surg 2011;40:1246-51.

106. Qiu Y, Lin XX, Ma G, et al. Eighteen cases of soft tissue atrophy after intralesional bleomycin A5 injections for the treatment of infantile hemangiomas: a long-term followup. Pediatr Dermatol 2015;32:188-91.

107. Chang L, Chen H, Yang X, et al. Intralesional bleomycin injection for propranolol-resistant hemangiomas. J Craniofac Surg 2018;29:e128-30.

108. Pandey V, Tiwari P, Sharma SP, et al. Role of intralesional bleomycin and intralesional triamcinolone therapy in residual haemangioma following propranolol. Int J Oral Maxillofac Surg 2018;47:908-12.

109. Düzenli Kar Y, Ozdemir ZC, Acu B, et al. Infantile hemangioma: efficacy of low-dose propranolol and of intralesional bleomycin injection for propranolol nonresponse. Pediatr Int 2019;61:459-64.

110. Sloan GM, Reinisch JF, Nichter LS, et al. Intralesional corticosteroid therapy for infantile hemangiomas. Plast Reconstr Surg 1989;83:459-67.

111. Gawrych E, Walecka A, Rajewska J, et al. [Intralesional corticosteroid therapy in infantile hemangiomas]. Ann Acad Med Stetin 2009;5 5:15-21.

112.Pandey A, Gangopadhyay AN, Sharma SP, et al. Evaluation of topical steroids in the treatment of superficial hemangioma. Skinmed 2010;8:9-11.

113. Couto JA, Greene AK. Management of problematic infantile hemangioma using intralesional triamcinolone: efficacy and safety in 100 infants. J Plast Reconstr Aesthet Surg 2014;67:1469-74.

114.Emir S, Gurlek Gokcebay D, Demirel F, et al. Efficacy and safety of intralesional corticosteroid application for hemangiomas. Turk J Med Sci 2015;45:335-8.

115.Wang Y, Zhu F, Ning JL, et al. Application of 1\% lauromacrogol in the treatment of facial refractory hemangioma and vascular malformations. Zhonghua Zheng Xing Wai Ke Za Zhi 2012;28:428-31.

116.Yu W, Zhang B, Li Q, et al. Efficacy of lauromacrogol in the management of infantile hemangiomas. J Clin Dermatol 2014;43:567-9.

117.Zhu X, Guo X, Liu D, et al. Significant inhibition of infantile hemangioma growth by sustained delivery of urea from liposomes-in-microspheres. Oncol Rep 2018;39:109-18.

118. Wang Z, Li J, Xu X, et al. Urea immunoliposome inhibits human vascular endothelial cell proliferation for hemangioma treatment. World J Surg Oncol 2013;11:300.

119.Perez Payarols J, Pardo Masferrer J, Gomez Bellvert C. Treatment of life-threatening infantile hemangiomas with vincristine. N Engl J Med 1995;333:69.

120.Perez J, Pardo J, Gomez C. Vincristine--an effective treatment of corticoid-resistant life-threatening infantile hemangiomas. Acta Oncol 2002;41:197-9.

121. Wasserman JD, Mahant S, Carcao M, et al. Vincristine for successful treatment of steroid-dependent infantile hemangiomas. Pediatrics 2015;135:e1501-5.

122. Sgonc R, Fuerhapter C, Boeck G, et al. Induction of apoptosis in human dermal microvascular endothelial cells and infantile hemangiomas by interferon-alpha. Int Arch Allergy Immunol 1998;117:209-14.

123. Chang E, Boyd A, Nelson CC, et al. Successful treatment of infantile hemangiomas with interferon-alpha-2b. J Pediatr Hematol Oncol 1997;19:237-44.

124.Zhang L, Zheng JW, Yuan WE. Treatment of alarming head and neck infantile hemangiomas with interferonalpha2a: a clinical study in eleven consecutive patients. Drug Des Devel Ther 2015;9:723-7.

125. Damas Mateache B, Menendez Suso JJ, Abelairas Gomez JM, et al. [Interferon alpha and infantile orbital hemangioma]. Arch Soc Esp Oftalmol 2003;78:623-9.

126. Michaud AP, Bauman NM, Burke DK, et al. Spastic diplegia and other motor disturbances in infants receiving interferon-alpha. Laryngoscope 2004;114:1231-6.

127. Mortureux P, Pedespan JM, Greselle JF, et al. Treatment of severe cervicofacial hemangioma with interferon alpha2b. Arch Pediatr 1995;2:237-40.

128. Léauté-Labrèze C, Labbe L, Grenier N, et al. Severe hemangiomas treated with interferon alpha-2b: seven cases. Ann Dermatol Venereol 1998;125:174-8.

129.Zhang W, Chen G, Wang FQ, et al. Macrophages contribute to the progression of infantile hemangioma by regulating the proliferation and differentiation of hemangioma stem cells. J Invest Dermatol 2015;135:3163-72.

130. Wu KQ, Muratore CS, So EY, et al. M1 macrophageinduced endothelial-to-mesenchymal transition promotes infantile hemangioma regression. Am J Pathol 2017;187:2102-11.

131.Li M, Chen Y, Guo Z, et al. The pigment epitheliumderived factor (PEDF): an important potential therapeutic 
agent for infantile hemangioma. Arch Dermatol Res 2017;309:169-178.

132.Itinteang T, Chudakova DA, Dunne JC, et al. Expression of cathepsins B, D, and G in infantile hemangioma. Front Surg 2015;2:26.

133. Chisholm KM, Chang KW, Truong MT, et al. BetaAdrenergic receptor expression in vascular tumors. Mod Pathol 2012;25:1446-51.

134. Dal Monte M, Filippi L, Bagnoli P. Beta3-adrenergic receptors modulate vascular endothelial growth factor release in response to hypoxia through the nitric oxide pathway in mouse retinal explants. Naunyn Schmiedebergs Arch Pharmacol 2013;386:269-78.

135. Amaya CN, Wians FH Jr, Bryan BA, et al. Enhanced expression of programmed cell death $1(\mathrm{PD}-1)$ protein in benign vascular anomalies. Pathology 2017;49:292-6.

136. Cai Y, Lv F, Kaldybayeva N, et al. 15, 16-Dihydrotanshinone I inhibits hemangiomas through inducing pro-apoptotic and anti-angiogenic mechanisms in vitro and in vivo. Front Pharmacol 2018;9:25.

137.Wang Y, Li M, Dong C, et al. Linc00152 knockdown inactivates the $\mathrm{Akt} / \mathrm{mTOR}$ and Notch1 pathways to exert its anti-hemangioma effect. Life Sci 2019;223:22-8.

138. Liu X, Lv R, Zhang L, et al. Long noncoding RNA expression profile of infantile hemangioma identified by microarray analysis. Tumour Biol 2016. [Epub ahead of print].

139.Zhang J, Zhang C. Silence of long non-coding RNA UCA1 inhibits hemangioma cells growth, migration and invasion by up-regulation of miR-200c. Life Sci 2019;226:33-46.

140. Cheng J, Liu B, Lee HJ. Outcomes of surgical treatment for hemangiomas. Pediatr Dermatol 2019;36:207-12.

141. Cho YK, Ryu DW, Chung HY, et al. Surgical management of scalp infantile hemangiomas. J Craniofac Surg 2015;26:1169-72.

142. Anderson RR, Parrish JA. Selective photothermolysis: precise microsurgery by selective absorption of pulsed radiation. Science 1983;220:524-7.

143. Tan OT, Murray S, Kurban AK. Action spectrum of vascular specific injury using pulsed irradiation. J Invest Dermatol 1989;92:868-71.

Cite this article as: Chen ZY, Wang QN, Zhu YH, Zhou LY, Xu T, He ZY, Yang Y. Progress in the treatment of infantile hemangioma. Ann Transl Med 2019;7(22):692. doi: 10.21037/ atm.2019.10.47
144. Chinnadurai S, Sathe NA, Surawicz T. Laser treatment of infantile hemangioma: a systematic review. Lasers Surg Med 2016;48:221-33.

145. Batta K, Goodyear HM, Moss C, et al. Randomised controlled study of early pulsed dye laser treatment of uncomplicated childhood haemangiomas: results of a 1-year analysis. Lancet 2002;360:521-7.

146. Kono T, Sakurai H, Groff WF, et al. Comparison study of a traditional pulsed dye laser versus a long-pulsed dye laser in the treatment of early childhood hemangiomas. Lasers Surg Med 2006;38:112-5.

147. Rizzo C, Brightman L, Chapas AM, et al. Outcomes of childhood hemangiomas treated with the pulsed-dye laser with dynamic cooling: a retrospective chart analysis. Dermatol Surg 2009;35:1947-54.

148. Asilian A, Mokhtari F, Kamali AS, et al. Pulsed dye laser and topical timolol gel versus pulse dye laser in treatment of infantile hemangioma: a double-blind randomized controlled trial. Adv Biomed Res 2015;4:257.

149. Reddy KK, Blei F, Brauer JA, et al. Retrospective study of the treatment of infantile hemangiomas using a combination of propranolol and pulsed dye laser. Dermatol Surg 2013;39:923-33.

150. Witman PM, Wagner AM, Scherer K, et al. Complications following pulsed dye laser treatment of superficial hemangiomas. Lasers Surg Med 2006;38:116-23.

151.Zhong SX, Tao YC, Zhou JF, et al. Infantile hemangioma: clinical characteristics and efficacy of treatment with the long-pulsed 1,064-nm neodymium-doped yttrium aluminum garnet laser in 794 chinese patients. Pediatr Dermatol 2015;32:495-500.

152. Stier MF, Glick SA, Hirsch RJ. Laser treatment of pediatric vascular lesions: port wine stains and hemangiomas. J Am Acad Dermatol 2008;58:261-85.

153. Brauer JA, Geronemus RG. Laser treatment in the management of infantile hemangiomas and capillary vascular malformations. Tech Vasc Interv Radiol 2013;16:51-4.

154. Brightman LA, Brauer JA, Terushkin V, et al. Ablative fractional resurfacing for involuted hemangioma residuum. Arch Dermatol 2012;148:1294-8. 